\title{
Transformative consumer research: Its origins and possible enrichment of the field of consumer research in South Africa
}

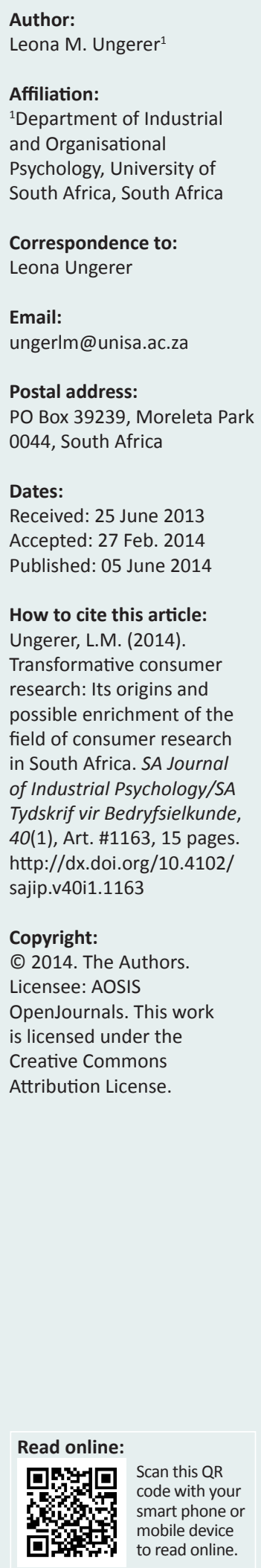

Orientation: This article provides a rationale for considering transformative consumer research as a research approach for investigating the relationship between consumption and consumers' well-being in South Africa.

Research purpose: The purpose of this study is to explore the principles underlying transformative consumer research, including how it differs from traditional research methods and pointing out some established research areas in this field.

Motivation for the study: Apart from pointing to a lack of literature, this article highlights the relevance of this approach for emerging countries by investigating the principles and practices embedded in transformative consumer research. It provides some indication of how an investigation of these areas may contribute to enhancing the relevance of consumer research to its various stakeholders.

Research design, approach and method: The author used a literature review to conduct the study.

Main findings: It appears that consumer research currently lacks external and internal relevance. A transformative consumer-research approach may address some of the fundamental problems in the way consumer psychologists plan and conduct their research, contributing to this lack of relevance.

Practical/managerial implications: Most stages of the traditional research approach may need to be adapted for transformative research purposes. Some approaches appear particularly suited to transformative consumer research, including revelatory, incendiary, policy, participatory and coalition research.

Contribution/value-add: This study's primary contribution stems from suggesting a rather novel additional approach to enhance the relevance of consumer research in South Africa, pointing out some established practices in the field of transformative consumer research and suggesting how they may augment consumer research in South Africa.

\section{Introduction}

In 2011, South African media reported on $i$ 'khothane, a 'youth craze', in Johannesburg's townships where groups of young people gathered around participants who burnt designer clothes and shoes worth thousands of rand to signify their wealth by being apathetic to such items (Jones, 2013). In her research, Mkhwanazi (2011) used the term 'pexing' to refer to this phenomenon. She explains that 'UkuPeksa' is a colloquial term developed by youth who take part in this activity, and it refers to different things based on the township in which it takes place.

Despite ascribing different terms to this trend, the views of the above two authors with regard to this phenomenon largely correspond. Jones (2013) equates i'khothane to 'conspicuous destruction' since it appears as if it is no longer enough to merely be able to afford expensive clothing and 'bling'; participants have to be rich enough not to need it. Mkhwanazi (2011), in contrast, posits that pexing corresponds to conspicuous consumption but also entails aspects that are distinct to it and proposes the term 'destructive conspicuous consumption' for this activity.

Local communities have been especially shocked at the attitude of wastefulness reflected in this destructive behaviour (Jones, 2013). Mkhwanazi (2011) further explains that youths taking part in pexing are often from environments that do not support such expensive destructive consumption, including often being from low-income families and having their parents disapprove of their conduct (if they knew). 
The media coverage generated public interest in what is driving pexing and the consequences for the people involved (Mkhwanazi, 2011). When the media called upon academics to explain this trend, some initial views were offered, but no empirical research on the subject has been published to date (Jones, 2013; Mkhwanazi, 2011).

It is evident from the above that consumers interact with products in complex ways. Existing theories and approaches to consumer research, however, may not sufficiently explain emerging trends in consumer behaviour. Mick, Pettigrew, Pechmann and Ozanne (2012a), for instance, point to the urgent need for applied research that incorporates rich theories and methodological rigour and that add to an understanding of the negative influences of consumption (and alleviate them) and lead to an understanding of and build on the positive influences of consumption. This may be particularly essential in the context of a developing economy where phenomena such as high levels of poverty, illiteracy, homelessness and unemployment require reconsidering the relevance of consumer research in understanding consumers' life worlds.

\section{Purpose of the study}

Consumption plays an essential role in most peoples' lives (Ganglmair-Wooliscroft \& Lawson, 2011). Mick et al. (2012a) further point out that human well-being is intricately linked to acquiring, consuming and disposing goods and services. Mick et al. (2012a, p. 3) actually suggest that 'consumption now facilitates a myriad of purposes and consequences, from nourishment, contentment, and achievement to gluttony, disfranchisement and destruction'.

A number of changes in society indicate the need for consumer research that closely focuses on well-being, including the impact of consumption on the global natural environment, acute economic imbalances that create political and social tensions, thus jeopardising peace and security, and the escalating household debt and widespread addictions to a range of consumer products and activities. Finally, what Mick, Pettigrew, Pechmann and Ozanne (2012b) term 'hand-held computers' and the Internet present a nearly immeasurable range of information and interactive venues for consumers to pursue their needs and desires.

The abovementioned societal changes are probably experienced in varying degrees globally. In addition to these societal changes, consumers from developing countries may face constraints in their choices which are not addressed in traditional models of consumer decision-making. Henrich, Heine and Norenzayan's (2010), for instance, suggest that psychological reports in global top journals are largely based on Western, educated, industrialised, rich and democratic (WEIRD) people. Since their findings reflect the life spheres of participants that, typically, are WEIRD, they often do not reflect the largest part of the human population. Although this situation may have improved in the meantime, Al-Wugayan and Suprenant (2006) further point out that most existing knowledge about consumer behaviour is based on research undertaken in America and a few Western European nations, comprising less than $6 \%$ of the world population.

This article posits that developing countries such as South Africa provide ample opportunities for research on the association between consumption and consumers' wellbeing and that the principles and processes underlying transformative consumer research should enrich this type of research. Incorporating these principles and processes should enhance the relevance of consumer research in general.

The section that follows firstly considers what is termed the 'seven sins' of consumer psychology, pointing out some fundamental problems in current consumer research. The concept of the 'bottom of the pyramid consumer' is then introduced since poverty is widespread in developing countries, and it impacts on consumers' consumption experiences. Consumer-culture theory (CCT) is briefly discussed since it would typically provide an understanding of conspicuous consumption. An introduction to transformative consumer research concludes the section.

\section{Current theoretical perspectives The 'seven sins' of consumer psychology}

According to Pham (2013), the field of consumer psychology is well-established in many respects. It, amongst others, became more inclusive since a larger base of researchers and a broader range of institutions contribute to top journals than before.

Despite this positive state of affairs, Pham (2013) warns that consumer research currently lacks internal and external relevance. Research findings often do not offer sufficient relevance and impact for external stakeholders such as businesses, policy makers and consumers as well as for internal stakeholders, including other consumer researchers and social scientists.

Pham (2013) posits that this unfavourable situation results from seven fundamental problems in the way consumer psychologists plan and conduct their research (the 'seven sins' of consumer psychology), namely:

- a limited view of the scope of consumer-behaviour research

- using a limited number of theoretical perspectives to examine relevant topics

- keeping to a narrow epistemology of consumer research

- mainly investigating psychological processes and not psychological content or the mental contents on which these processes operate

- generalising from limited empirical evidence

- considering methodological convenience instead of the substantial contributions that they make when designing studies

- persistent confusion between 'theories of studies' and 'studies of theories' - what passes as empirical studies 


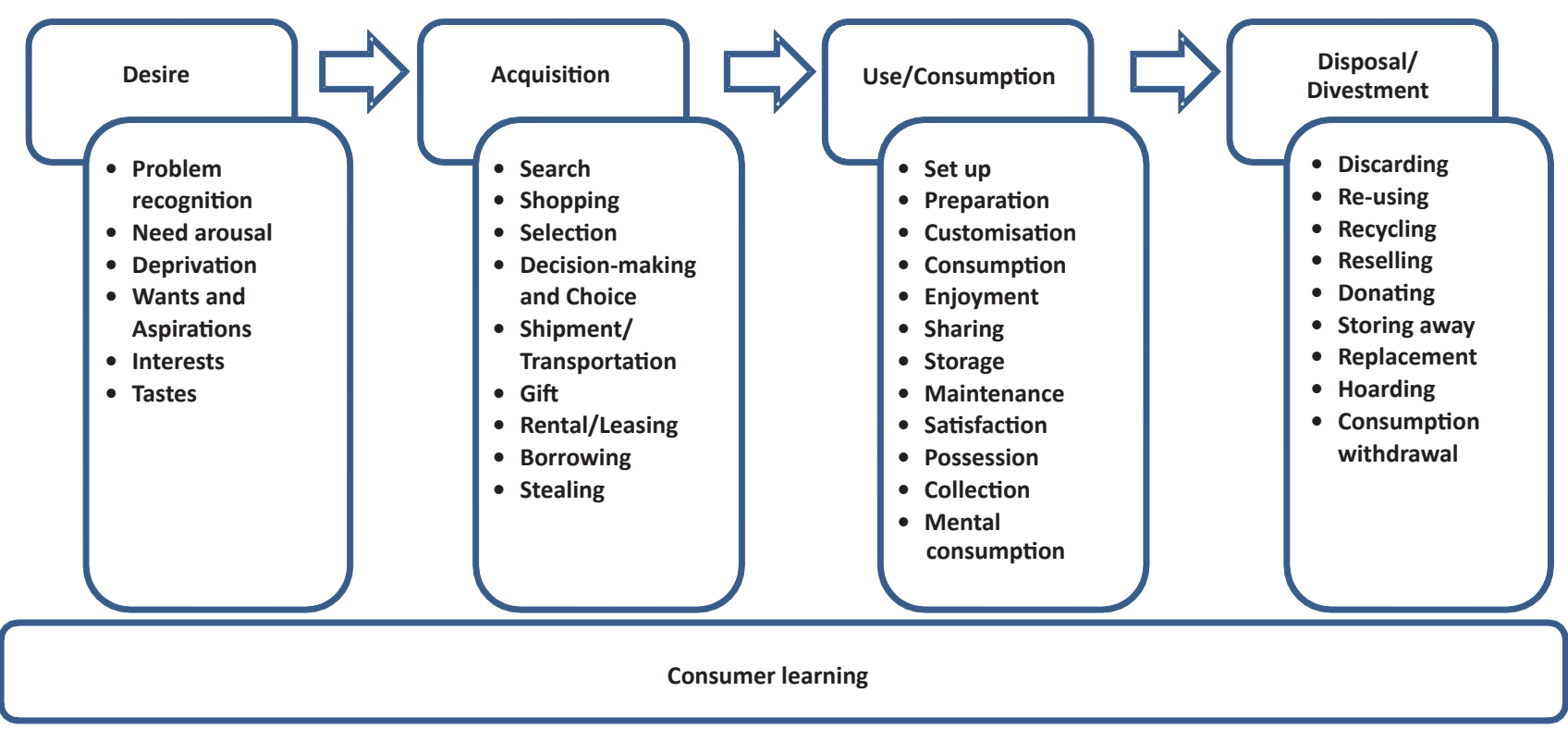

Source: Pham, M.T. (2013). The seven sins of consumer psychology. Journal of Consumer Psychology, 23(4), 414

FIGURE 1: The scope of consumer behaviour.

testing novel theoretical propositions about consumer behaviour ('studies of theories') often merely reflects the conceptualisation of very narrow phenomena that are created by the studies themselves ('theories of studies').

A transformative consumer-research approach may address most of the above concerns to some extent, but it is particularly appropriate for addressing Pham's (2013) concern about the limited view of consumer-behaviour research.

\section{Limited range of topics covered in consumer behaviour}

Pham (2013) believes that the restricted range of topics typically studied in consumer behaviour constrains consumer research severely. He (Pham, 2013, p. 413) points out that a commonly accepted definition of consumer behaviour would be: 'How consumers come to learn about, desire, acquire, use, and dispose of goods, services, and activities available in the marketplace to satisfy their needs.'

In line with the above, students at higher-education institutions are often introduced to well-known models of consumer decision-making such as those by Blackwell, Miniard and Engel (2006), Evans, Jamal and Foxall (2009), Schiffman, Kanuk and Wisenblit (2010), and Solomon, Askegaard and Bamossy (2006). The essence of these models is reflected in Pham's (2013) representation of the scope of what is commonly accepted as 'consumer behaviour' (Figure 1). It is often presented as a sequence of stages that starts when consumers develop a desire for a product or service that they believe may satisfy their needs. After taking part in a number of possible processes to acquire the product or service, consumers use and consume the purchased item. The process concludes when consumers dispose of the particular product or service.

Pham (2013), however, points out that consumer research generally focuses on the acquisition stage of consumer behaviour. Studies typically investigate the factors that predict purchasing behaviour such as consumer attitudes, the process of persuasion, the search strategies and consideration consumers employ and how they make decisions. However, it is evident from Figure 1 that purchasing behaviour constitutes only a small portion of all consumption-related activities, and consumer research may neglect major areas of consumer behaviour by mainly focusing on purchasing behaviour.

Pham (2013) ascribes consumer psychology's historical focus on purchasing behaviour to the supposition that it is particularly relevant from a managerial viewpoint. He, however, suggests that businesses are also interested in additional stages of consumer behaviour such as the desire stage (reflecting consumers' needs and wants) and the use and consumption stage. An understanding of how consumers use products and services is essential for policy makers. Issues such as whether they comply with drug regulations, whether they take part in gambling and whether they appropriately use limited natural resources may be relevant. Further areas of interest to policy makers include the factors that initially motivate consumers' consumption of a product or service and their detachment from the consumption process. For instance, how do they overcome drug or alcohol addiction, and do they engage in recycling? 
Pham (2013) further points out alternative types of acquisition such as borrowing, sharing, renting, receiving gifts, bartering and even stealing. These types of acquisition that are seldom considered significantly impact on business and the economy as a whole through, for instance, losses in a retail environment due to theft. Pham (2013) also suggests investigating the psychology of consumption-need deprivation which, amongst others, may result from poverty. Although topics such as these may be investigated from various theoretical perspectives (adding to their richness as research areas) and hold considerable practical relevance, they have not yet been adequately investigated in the field of consumer psychology. Many opportunities for meaningful research contributions to the business world as well as consumer policy indeed lie beyond the mere study of purchasing behaviour.

\section{Consumer culture theory}

Consumer culture theory (CCT) typically provides the theoretical substantiation for tendencies in consumer behaviour such as conspicuous consumption (as evident in pexing). Arnould and Thompson (2005, p. 886) presented CCT as 'a family of theoretical perspectives that address the dynamic relationships between consumer actions, the marketplace, and cultural meanings'. An area of interest in CCT that is particularly relevant for the current study is the functioning and impact of consumer culture.

Arnould and Thompson (2005, p. 869) explain this concept as a social arrangement in which the relationships between lived culture and social resources, and between meaningful ways of life and the symbolic and material resources on which they depend, are mediated through markets.

In a consumer culture, the majority of consumers fervently crave goods and services that are valued for non-utilitarian reasons such as status and novelty seeking (Belk, 1988). CCT views individual consumers as functioning in a cultural, economic and political framework that shapes and limits how they think, feel and act in the marketplace (Nairn, Griffin \& Wicks, 2008).

\section{Consumers at the bottom of the pyramid}

Experts globally realised the value of understanding the lives of impoverished people during the last decade (Piacentini \& Hamilton, 2013). Despite significant progress in poverty alleviation, more than half of the world's population still lives in poverty (Blocker et al., 2013). Hart's (2002) original description of the bottom of pyramid (BOP) market encompassed approximately 4 billion consumers globally whose annual income is less than US\$1500 per year. Changing world demographics and economic conditions, however, necessitated a re-classification of this market. The World Bank classification, presenting BOP consumers as those who live on less than US\$1 per day was previously commonly accepted (Banerjee \& Duflo, 2006). In light of changing global income patterns since the World Bank classification in 1990, it was expanded to include households of consumers who live on less than US\$2 a day. This level encompasses consumers who are able to purchase a larger variety of basic products such as food and personal hygiene products and who have access to basic shelter and sanitation facilities (Rangan, Quelch, Herrero \& Barton, 2007).

All in all, poverty is a global concern and numerous consumers globally suffer the effects of poverty. Poor people face various restrictions such as limited choice (often amongst poorer-quality products and services) and reduced consumption capabilities (Blocker et al., 2013). Poor people living in a consumer culture particularly face the issue of coping with limited economic resources. Bertrand, Mullainathan and Shafir (2006) further argue that, although all consumers may face difficulties in the marketplace, poor consumers can afford fewer mistakes. Hill (2001) points out that impoverished people in both developing and developed countries share a sense of deprivation since they struggle to meet the consumption requirements for a 'minimally decent' life.

\section{Transformative consumer research}

Mick (2006) is credited with developing the concept of transformative consumer research. In his presidential address to the Association of Consumer Research (ACR), he urged his colleagues to consider more closely the meaning of their research based on its implications for and impact on social issues. He proposed that transformative consumer research should have 'an immediate practical orientation' (Baker, 2011).

Transformative consumer research involves researchers taking a more consumer-focused position and ascribing particular importance to societal welfare. It aims to encourage, support and publish research that enhances consumer welfare and the quality of life of all who are affected by consumption globally (Mick et al., 2012a). This type of research stems from scholars' increasing realisation that current research does not adequately address problems relevant to the whole of humankind (Crockett et al., 2013).

Researchers supporting the transformative consumerresearch movement study the role of consumption in relation to major social problems such as when obese, addicted or highly materialistic people compulsively consume products or when the hungry, the homeless and the poor do not have access to sufficient products (and services) for sustaining their well-being (Ozanne, Pettigrew, Crockett, Downey, Firat $\&$ Pescud, 2011). Transformative consumer research focuses on practical research which stakeholders such as consumers, activists, policy makers and businesses can apply to improve consumer well-being. In essence, such research aims at avoiding negative consumer outcomes and attaining positive ones (Petkus, 2010).

Some general transformative consumer research topics include vulnerable populations (such as the poor, illiterate and elderly), negative consumer behaviour (including smoking, poor nutritional habits and high-risk behaviour) and 
positive consumer behaviour (for instance, environmentallyresponsible behaviour, volunteer work and organ donation) (Petkus, 2010).

In the past, consumer research mainly followed positivist paradigmatic approaches to generate knowledge. More interpretive and post-positivist research approaches have recently entered the field (Arnould \& Thompson, 2005). Despite an apparent increased diversity, the prevailing paradigms mainly aim at understanding or explaining behaviour instead of partnering with consumers in order to change behaviour and consequently enhance well-being (Ozanne \& Saatcioglu, 2008).

Askegaard and Scott (2013) posit that the transformative consumer research group has a definite activist orientation since the force behind the initial paradigm shift was not only based on methodological or disciplinary convictions but also on political convictions. Many researchers from this movement felt that marketing scholars ignored the power imbalances and negative social impact endemic to the marketplace and believed that mainstream scholars conspired with industry by declaring that the purpose of research should be to assist marketers in increasing sales.

Mari (2008) further suggests that controversies, criticism and problems around the role of marketing in society indicate that scholars should approach consumers to obtain a better understanding of the role of marketing in their lives. Marketing and consumer research cannot measure the relevance of marketing in consumers' lives from a perspective that mainly investigates managerial implications. Transformative consumer research therefore involves understanding consumer behaviour for the benefit of consumers themselves and not for business organisations.

\section{Marketing and consumer well-being}

A common conception is that marketing impacts on consumer well-being. Sirgy, Lee and Rahtz (2008, p. 378) define consumer well-being as a desired state of objective and subjective well-being involving the various stages of the consumer or product life cycle in relation to consumer goods. Sirgy et al. (2007) point out that marketing has a fundamental impact on consumer well-being in light of its direct impact on consumers' satisfaction in the consumer life sphere (experiences related to the marketplace) and its indirect impact on other life spheres such as health and safety, work, family, leisure and finance.

Andreasen, Goldberg and Sirgy (2012) distinguish between the 'dark side' and the 'bright side' of marketing's social impact. Dark-side elements point toward the trend that a range of marketing strategies and tactics potentially, and often in reality, negatively impact on consumers' well-being and/or the well-being of the broader societies in which they live. Such impact includes obvious deception, the promotion of undesirable values and behaviour and disregarding the needs of society's most vulnerable groups. Bright- side considerations include the ways in which marketing practices may improve people's lives and the world they live in. Recent developments in this field are broadly classified as social marketing.

The distinction between dark-side and bright-side topics surrounding consumer well-being can be used to classify most research on consumers' quality of life. Research on materialism, compulsive shopping and consumption equity can be considered as reflecting the dark side of consumer well-being. Quality-of-life research dealing with specific consumer populations, the consumption life cycle, consumerlife satisfaction, consumers' perception of a product's impact on their quality of life and how their need satisfaction and goals relate to subjective well-being represent the bright side of consumer well-being.

The transformative consumer-research goal for dark-side topics is to suggest social programmes or policies that may reduce the negative effects of marketing practices on consumer well-being and society in general. In contrast, the transformative consumer-research goal for bright-side topics is to suggest marketing strategies and practices that can enhance consumers' positive experience in the marketplace, thereby enhancing their quality of life.

\section{Problem statement and research objectives}

All the phenomena typically investigated in transformative consumer research (Mick et al., 2012b; Petkus, 2010) probably are prevalent in South Africa, but some may require more urgent investigation than others. Shultz and Shapiro (2012) point out that all developing economies have distinguishing characteristics, but South Africa has a particularly unusual history and set of challenges, including poverty, the devastation caused by HIV and continuous consumer and societal transformation.

Furthermore, South Africa is known for its inequality in terms of the distribution of wealth as reflected in one of the highest Gini coefficients in the world (0.62 in 2012) (see Point of Purchase Advertising International [POPAI] \{n.d.\}). A Gini coefficient of ' 1 ' is an indication of complete income inequality with the wealthiest $1 \%$ of the population earning all the income whereas a Gini coefficient of ' 0 ' is indicative of complete equality with everybody earning an equal income. Van Aardt (as cited in Shevel \& Klein, 2008) further indicates that, although there has been a significant increase in the wealth of black consumers, nearly 22.5 million South Africans live on the breadline or below. Associated with this, South Africa has a substantial number of consumers, such as the poor and illiterate, who would typically be regarded as vulnerable.

In a consumption context, consumer vulnerability indicates a state of helplessness related to power imbalances in people's interactions in the marketplace (Baker, Gentry \& Rittenburg, as cited in Blocker et al., 2013), generating a lack of confidence and the propensity to experience risk, shocks and stress (Wratten, 1995). 
Transformative consumer research offers substantial potential for improving the lives of human beings in developing economies, particularly the vulnerable (Schultz \& Shapiro, 2012). The profusion of vulnerable consumers in South Africa points to the need not only to investigate why and how people make (and are sometimes forced to make) the consumption choices they do but also how those choices impact on their well-being (Petkus, 2010).

Menzel Baker, Gentry and Rittenburg (2005) further suggest that consumer vulnerability is a condition and not a status. Although some groups of people (such as people from particular demographic groups or types of communities) tend to be more prone to vulnerability, all people from such groups would not necessarily experience vulnerability.

Since the aim of transformative consumer research is to achieve flourishing, this research approach may contribute to an understanding of, amongst others, the life spheres of vulnerable consumers, for instance how they cope with restricting circumstances and how their conditions can be improved. Consequently, the section that follows captures the problem statement that is central to this article.

How can transformative consumer research enhance the relevance of consumer research in a developing country such as South Africa?

In lieu of the above problem statement, this article will focus on four research objectives:

- to investigate the unique qualities and commitments guiding transformative consumer research

- to investigate how transformative consumer research differs from traditional consumer research

- to consider the relevance of some transformative consumer-research topics for the South African situation

- to investigate the relevance of incorporating transformative consumer research into higher-education curricula.

\section{Rationale for, or value of the study}

Compared to traditional consumer research, transformative consumer research typically widens the range of problems investigated as well as the stakeholders reached. Although various consumer research scholars and presidents of the ACR tried to inform mainstream academic circles of the opportunities that transformative consumer research offers, most academic journals are not directly involved with the needs of consumers or their representatives (Crocket et al., 2013). Yadav (2010) advises that, in light of the complexity of transformative consumer-research issues, it is essential to develop new theories, to investigate their significance and to encourage research in the field's leading journals.

Special issues of the Journal of Consumer Research (October 2008), the Journal of Macromarketing (December 2007), the Journal of Public Policy and Marketing (Spring 2011) were dedicated to the concept of consumer well-being, signifying the increasing pertinence of investigating problems that are particularly relevant to consumers and the need that agents of social change should have access to such research findings (Pancer \& Handelman, 2012). More recently, a special edition of the Journal of Business Research (August, 2013) was devoted to transformative consumer research.

Although Ungerer (2013) points to the significance of transformative consumer research in understanding consumer well-being, the author could not locate a publication in the literature that recommended investigating the relevance of this approach for South African conditions. This study adds to the academic body of knowledge about developments in consumer research in this country by expositing the basic principles of transformative consumer research, indicating how it differs from traditional consumer research, pointing out some of the areas that are investigated in this field and suggesting its incorporation in academic curricula.

\section{Research design Research approach}

The arguments in this article mainly adhere to the main tenets proposed in the field of transformative consumer research. The key principles underlying transformative consumer research served as guidelines for building the key arguments.

\section{Research method}

Given the aims of this article, the author chose a literature review as research strategy. This enabled her to provide a theoretical substantiation for how transformative consumer research may add to the array of research approaches that could enhance the relevance of consumer research in South Africa.

Boote and Beile (2005) suggest that good quality research promotes people's collective understanding in a field. To advance such collective understanding, a researcher needs to understand what has been done before. A literature review assists in positioning existing literature in a broader scholarly and historical context. The literature review identifies what still needs to be learned and accomplished. It enables the author to summarise existing literature and to integrate it in a way that generates a new perspective.

\section{Targeted body of literature}

The author mainly conducted data searches on Google Scholar ${ }^{\mathrm{TM}}$ and then accessed the relevant online scholarly journals by means of search engines such as EbscoHost, Taylor \& Francis Online, Emerald, Business Source Complete and Sage Publishing. The author sourced information by mainly focusing on the concepts of transformative consumer research, consumer vulnerability and consumer well-being.

The author searched a wide range of publications to ensure that adequate data supported the conclusions she drew. She 
consulted both local and international literature but could not identify a substantial amount of locally published literature on transformative consumer research.

A publication that appeared in most of Google Scholar ${ }^{\mathrm{TM}}$ searches is a large edited volume of 33 chapters focusing on transformative consumer research (Mick et al., 2012a). The contributors to this publication represent several disciplines from universities and institutions globally (particularly some of the most knowledgeable and distinguished consumer researchers), and it covers a wide spectrum of the prevalent problems and opportunities regarding consumer behaviour that are associated with various dimensions of well-being (Mick et al., 2012a).

\section{Gathering the data}

The author gathered data specifically to meet the objectives of this article. Keywords contained in this article were the instruments for gathering the data. These key phrases included, in order of importance, transformative consumer research, consumer vulnerability, consumer well-being and higher education and South Africa.

The author then evaluated the body of literature for inclusion in this article. She evaluated it against the general principles of transformative consumer research. In addition, she closely examined the research articles in terms of their relevance for adding new knowledge to the field of consumer research in South Africa. As a final step, the author integrated the data to present a substantiated argument for considering the role of transformative consumer research in enhancing the relevance of consumer research in South Africa.

\section{Analysis of the data}

Consistent with her approach to collecting data, the author analysed the data in terms of the value that the themes she identified may add to an understanding of the contribution of transformative consumer research to enhance the relevance of consumer research in a developing-country context. The author evaluated the data she gathered against the principles of transformative consumer research to determine how much each of the themes could contribute to an understanding of the unique qualities of this field.

\section{Presentation of the data}

The data is presented in four sections: The first section entails the core commitments of transformative consumer research. This section is mainly based on the views of four of the most prolific researchers in the field of transformative consumer research and the editors of the most comprehensive publication about transformative consumer research to date, namely Mick, Pettigrew, Pechmann and Ozanne (see Mick et al., 2012a). The second section investigates how transformative consumer research differs from traditional research since the issues investigated in transformative consumer research tend to be broader than those customarily investigated in consumer research. The third section provides a brief overview of some of the areas investigated in transformative consumer research and indicate their relevance to South African conditions. Finally, the last section briefly offers suggestions for incorporating transformative consumer research into higher-education curricula.

\section{Results \\ Core qualities and commitments of transformative consumer research}

Although transformative consumer research is still a developing research programme, it has six set core commitments (Figure 2).

Each of the core commitments is now briefly discussed.

\section{To improve well-being}

The normative goal of transformative consumer research is to improve well-being, which is a state of flourishing that involves health, happiness and prosperity (Mick et al., 2012a). McGregor and Goldsmith (1998) point out seven dimensions of well-being: emotional, social, economic, physical, spiritual, environmental and political. Guided by a pragmatic and concrete orientation, transformative consumer research focuses on the issues and opportunities embedded in one or more of the dimensions of well-being.

Although transformative consumer research is unquestionably aimed at improving well-being, this goal creates some challenges. Globally, all people cannot independently enhance their well-being without considering the needs of others and the survival of the planet. Achieving widespread well-being in fact requires extensive deliberation

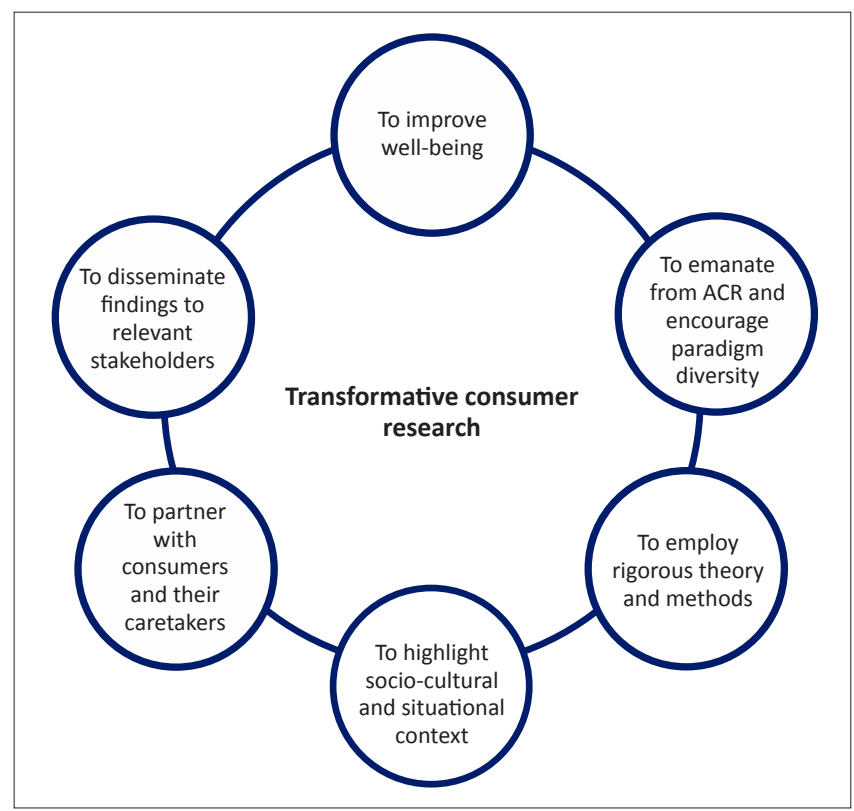

Source: Mick, D.G., Pettigrew, S., Pechmann, C., \& Ozanne, J.L. (2012a). Origins, qualities and envisionments of transformative consumer research. In D.G. Mick, S. Pettigrew, C. Pechmann $\&$ J.L. Ozanne, (Eds.), Transformative consumer research for personal and collective wellbeing (p. 6). New York: Taylor \& Francis.

FIGURE 2: The six core qualities and commitments of transformative consumer research. 
about how both individual and collective well-being can be met. Transformative consumer research consequently aims at improving well-being but at the same time enhancing social justice and the fair distribution of opportunities and resources. Open-mindedness, compassion and excellent scientific research are crucial in addressing this collective challenge (Mick et al., 2012a).

\section{To emanate from the Association for Consumer Research (ACR) and encourage paradigm diversity}

Transformative consumer research mainly evolved from the ACR. Mick et al. (2012a) believe that the ACR is particularly geared towards guiding and supporting consumer research on well-being in all its dimensions. It has consistently gained insight into the complexities of consumer behaviour over four decades and established a re-invigorated commitment to human and global welfare. The association has had an international orientation since its inception, and conferences are currently held in North America, Europe, Latin America and the Asia-Pacific region, encouraging the advancement of knowledge about transformative consumer research.

The ACR is dedicated to encouraging diverse research traditions. Attaining its shared mission of protecting and improving well-being requires the involvement of consumer researchers from all backgrounds and perspectives. A variety of theories, methods, levels of analysis and paradigms are necessary to expand knowledge about well-being and positively impact its increase. Transformative consumer research does not prescribe a particular paradigm, theory or method before the focus of a research study, its challenges, intended audience and uses are evident.

\section{To employ rigorous theory and methods}

Mick et al. (2012a) advise that, despite the pragmatism of transformative consumer research, researchers should never lose track of the importance of strong theory and methods. Rigorous theory and methods indeed are necessary to achieve applied goals. Compelling theory may provide in-depth insights into consumers' daily behaviour and their wellbeing, and trustworthy methods sustain reliable conclusions, implications and advice.

\section{To highlight socio-cultural and situational contexts}

Transformative consumer research emphasises the sociocultural context or situation in which the well-being problem or opportunity is embedded. For research to be meaningful, relevant and useful, the consumers' life world should always be considered. This does not imply that all transformative consumer research should be of an anthropological or sociological nature. Transformative consumer research, however, should focus on the problems that consumers find most pressing, and it should aim at developing solutions for conditions in which consumption and well-being most closely impact each other.
Physical and environmental factors and situational settings such as consumers' family and social settings further play an essential role in both well-being and consumption. Disregarding such factors would compromise the foundation of transformative consumer research. Mick et al. (2012a) believe that the requisite contextual consideration in transformative consumer research will enrich theory building and add to existing theories.

\section{To partner with consumers and their caretakers}

Given the goal of transformative consumer research to undertake meaningful and relevant research, researchers need to be both advocates for and partners of consumers. Scholars in this field aim to produce knowledge that can be directly converted into new abilities and behaviour for supporting well-being. They typically do not function in isolation or pursue mainly basic, theoretical, methodological or empirical discoveries. Mick et al. (2012a) rather portray researchers with this orientation as public servants who work towards achieving basic insights into consumer behaviour that could make consumers' lives healthier, safer and more rewarding.

\section{To disseminate findings to relevant stakeholders}

Transformative consumer research is both planned and performed bearing in mind that the resulting insights should be shared with consumers, policy makers or any stakeholders who may benefit from learning and applying the research results. Results should be presented in useful formats, and researchers need to collaborate with consumers to ensure that they find the research outcomes relevant and comprehensible.

\section{A comparison of transformative consumer- research and traditional consumer-research approaches}

Mick (2006, p. 6) points out that transformative consumer research requires undertaking studies that are built around a fundamental problem or opportunity and should be aimed at improving life 'in relation to the myriad conditions, demands, potentialities, and effects of consumption'. This ideal warrants investigating the appropriateness of existing methodological approaches for achieving transformative consumer-research goals.

According to Ozanne et al. (2011), consumer research methods that are customarily applied in initiating, performing and reporting on research may not be suitable for the broad-scale approach required in transformative consumer research. Consumer researchers typically work individually or in small groups, exploring distinct and carefully delineated elements of human behaviour at a specific time and publishing their results in peer-reviewed journals. Researchers who aim at investigating those consumption-related phenomena that consumers find particularly challenging may find this approach wanting. 
To transform consumer and consumption practices, research problems are typically conceptualised more broadly, considering the influence of a wide range of factors over extended periods of time. This often involves creative sampling and data-collection procedures, combined with more iterative and integrated approaches to data analysis. Finally, a new model for research dissemination is required for research outcomes to be expressed in organisational and individual practices and public policy (Ozanne et al., 2011).

Although transformative consumer research employs a variety of methodological approaches, some are particularly suited to this field (Crockett et al., 2013). The need to simultaneously generate theoretical advances in knowledge as well as practical outcomes that improve consumers' lives adds to the complexity of transformative consumer research.

Transformative consumer research is committed to engaging with agents of social change, but many academics produce studies exclusively aimed at the academic community and typically measure the impact of their work based on a citation index (Mick et al., 2012a). The all-encompassing mission of transformative consumer research, however, is to produce research that leads to greater well-being.

Mick et al. (2012a) explore five potential directions that relate to different agents of change that may particularly assist researchers in achieving some social impact. Revelatory and incendiary research aims at generating extensive social interest and involvement in particular social issues. Revelatory research, for instance, often involves at-risk groups such as the poor and the very young who do not have the necessary influence or resources to make their needs known. In terms of incendiary research, Mick et al. (2012a) suggest that, since a fairly small group of researchers write convincingly and clearly about important social issues, their ideas are widely read and disseminated to the public. The increasing attention to journals' impact factors further suggests that the dissemination of research ideas beyond academic circles is gaining importance.

Policy research, that is, research aimed at understanding and contributing to public policy, is a fairly established approach to consumer research. Governments impact significantly on the well-being of society by means of laws and regulations. Transformative consumer research can effect social change by, for instance, investigating problems that require greater governmental control and protection or by investigating the efficiency of existing policies.

Participatory research, also known as action research, collaborative research and community action research, typically partners with those people who are affected by a particular social problem. The people who are being researched become collaborators in the research process and gain valuable knowledge during this process.

In coalition research, researchers typically collaborate with organisations committed to alleviating a social problem. Researchers establish a continuing relationship with the people, group or organisation involved to undertake additional research and assist them further.

After reviewing the traditional research process from a transformative consumer-research perspective, Crockett et al. (2013) identify some elements that may need to be adapted, considering the multifaceted and highly complex problems that consumers currently face. Table 1 presents the flow of the research process with some implications of adopting a transformative consumer-research focus at each stage (with examples).

TABLE 1: Comparison of traditional and transformative consumer research.

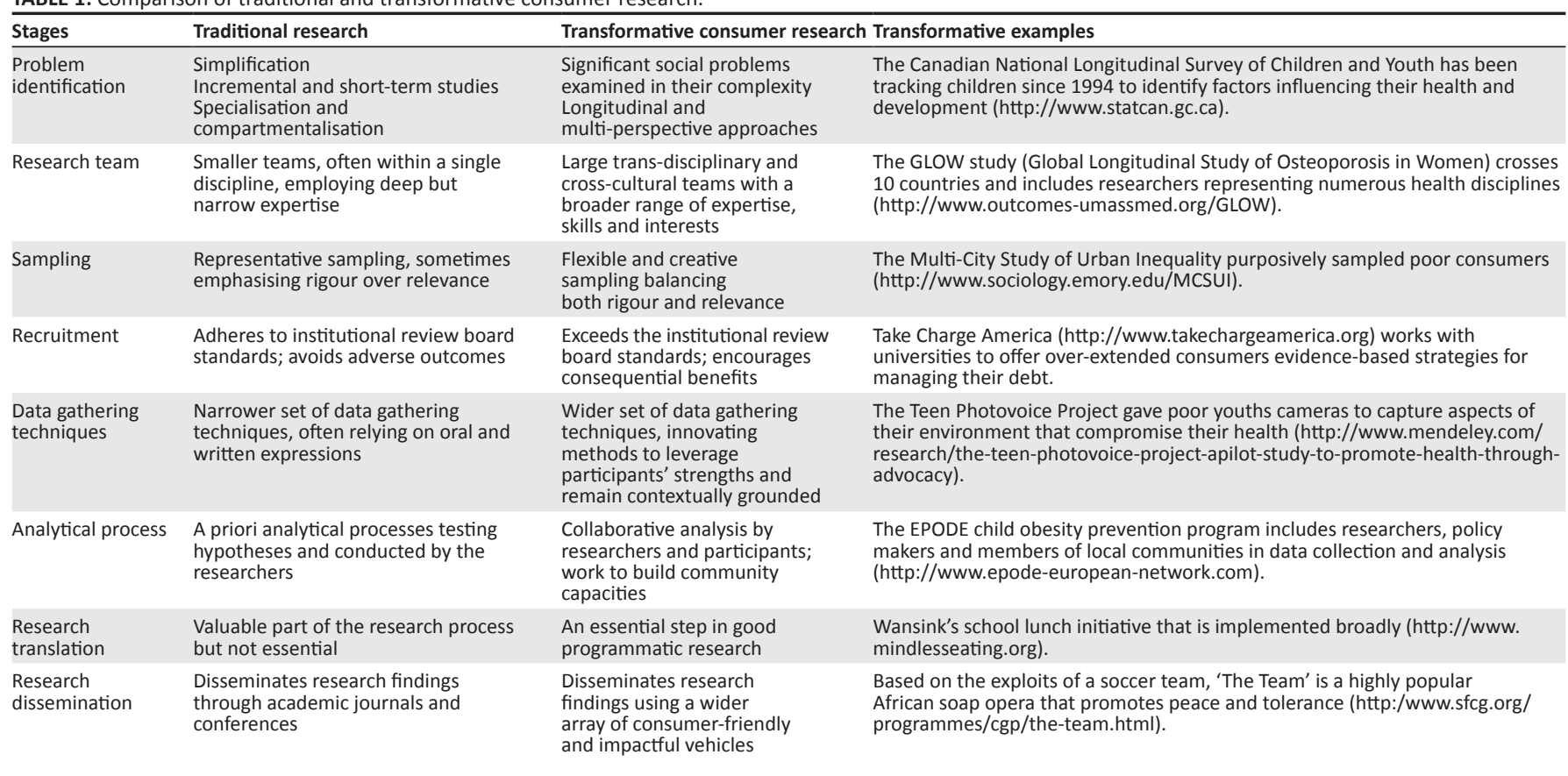




\section{Problem identification}

Issues such as poverty or global warming are often perceived as too complex to investigate within the boundaries of a single study or discipline. Researchers consequently rather conduct incremental, manageable and specialist studies.

A transformative consumer-research orientation encourages researchers to challenge established perspectives, findings and theories. It further tends to take a longer-term view on generating and publishing results than is commonly accepted. This may include designing large, longitudinal projects that incorporate a number of small-scale projects to generate preliminary results and then adapting them to large-scale projects that take place over time (Wansink, 2012).

\section{Research team}

To address extensive research problems, it is often necessary to compile large, trans-disciplinary teams that add a variety of knowledge, expertise and resources to the project (Stokhols, Misra, Moser, Hall \& Taylor, 2008). Such projects may require a longitudinal approach to include repeated data-collection and analysis phases (Klein, 2008). Although this type of research model is well-established in other disciplines, it is not common in business research (Crockett et al., 2013).

Over the past century, research about consumption primarily stemmed from two main disciplines, namely (1) consumer studies or sciences that branched from home economics and (2) consumer-behaviour research that branched from marketing (McGregor, 2013). Considerable global changes, however, took place since the establishment of these two disciplines, including the development of a global consumer culture, the establishment of a consumerism ideology and a corporate-led, top-down economic globalisation. To have a clear view of the requirements for addressing urgent social problems, especially those fuelled by consumption, academics need to be able to move across various disciplinary boundaries (Wilson 1998).

The range of knowledge and skills typically entrenched in trans-disciplinary teams enhance their ability to respond to changes in the research environment that commonly occur when a phenomenon is investigated over time. Academic reward systems that mainly support individual research and sole-authored publications, however, discourage the establishment of large, trans-disciplinary research teams (Crockett et al., 2013).

\section{Sampling}

According to Crockett et al. (2013), standard approaches to sampling may not be appropriate when investigating practical issues that impact consumer well-being. Applying representative sampling may not be feasible amongst consumers from diverse geographical areas, and consumers who are marginalised or unwilling to participate in research. Researchers may need to be open, flexible and creative when identifying suitable sampling procedures for such situations.

\section{Recruitment}

Both traditional and transformative researchers have to adhere to the requirements of institutional review boards when recruiting research participants. Crockett et al. (2013) identify various structural and procedural problems concerning institutional review boards in America, including a conflict of interest between protecting humans and encouraging research that generates funding and prestige for a particular university.

An essential concept in the above process is the requirement of informed consent. Transformative research, however, often investigates complex social problems with the involvement of trans-disciplinary teams, and some studies take place over extended periods of time and across various sites. Crockett et al. (2013) advise that the concept of informed consent be extended to include the on-going process of communication with participants during the research project as well as any changes that may occur during the research timeframe. Since transformative research aims at generating benefits for research participants, on-going dialogue on the benefits and costs of the research is required as participants are recruited and retained.

\section{Data gathering}

Transformative consumer research may necessitate novel approaches to data gathering. Despite the availability of a range of traditional research approaches, researchers tend to favour a smaller set of conventional methods that incorporate written language such as surveys and experiments. Many people, including the poor, are not highly literate. Established approaches such as focus groups and interviews further require participants to verbally express their views. This, however, can be problematic in cases where people are not able to or do not want to express their thoughts. In such cases, novel approaches may encourage participants to express their views, for instance, by providing them with cameras and asking them to visually document the meaning of a particular topic in their life (Burke \& Evans, 2011).

\section{Analysis}

To test proposed hypotheses, researchers often determine methods of analysis at the outset of a study. This approach assumes that the researcher as expert can determine the focus and scope of the study in advance and is then able to apply analytical techniques and interpret the results. Crockett $e t$ al. (2013) point out that, although this analytical process may provide information to community members for whom the research is conducted, they remain recipients of information instead of producers of research. In community-health research, researchers rather collaborate with community members to identify problems, design research, analyse results and create solutions (Minkler \& Wallerstein, 2003). This approach incorporates the idea that solutions generated jointly with communities tend to be considered more valuable and will more likely be used.

\section{Translation}

The term 'research translation' is mainly used in health research, but this process pertains to any research 
programme that is aimed at applying findings to bring about change. Research translation in essence involves, firstly, converting results into actionable insights for providers and then collecting insights from these applications to stimulate further research.

Since transformative consumer research aims to generate findings that will guide the actions of consumers, policy makers and managers, research translation should play a more important role in this field than is currently the case in consumer research. Crockett et al. (2013) point out that translation is a demanding task and that some researchers find it ineffective and disappointing. They, however, suggest that it is a worthy goal to strive for, generating insights that may enhance consumer empowerment.

\section{Dissemination}

To truly reach consumers, researchers should employ a broader range of communication vehicles than academic journals and professional conferences for disseminating their research findings (Crockett et al., 2013). The Internet, social media and consumer-friendly versions of articles in online academic journals offer valuable avenues for conveying information to targeted groups.

\section{Bias and external validity}

Finally, Crockett et al. (2013) point out that, just like other types of research, transformative consumer research is prone to biases. Since research problems are selected from a number of commendable topics, researchers often have to make value judgements and prioritise topics. Transformative consumer research further typically addresses sensitive issues, and consumer vulnerability may be overstated (Downey, Hamilton \& Catterall, 2007). Some of the bias inherent in this work could be addressed by being completely transparent throughout the research process (Ortlipp, 2008) and actively collaborating with those affected by a particular issue to ensure that their perspective is effectively represented.

In terms of its external validity, the fundamental value of transformative consumer research lies in how consumers use its results. Assessing this impact should always truly reflect local conditions.

\section{Topics investigated in transformative consumer research}

To provide an indication of the breadth of topics investigated in this field, Table 2 summarises some of the topics covered in Mick et al. (2012a).

\section{Relevance to South African conditions}

The author believes that some research in South Africa may already belong to the field of transformative consumer research although it is not identified as such. This approach holds considerable promise for research that is practically relevant in a developing country such as South Africa.

TABLE 2: Examples of topics covered in transformative consumer research.

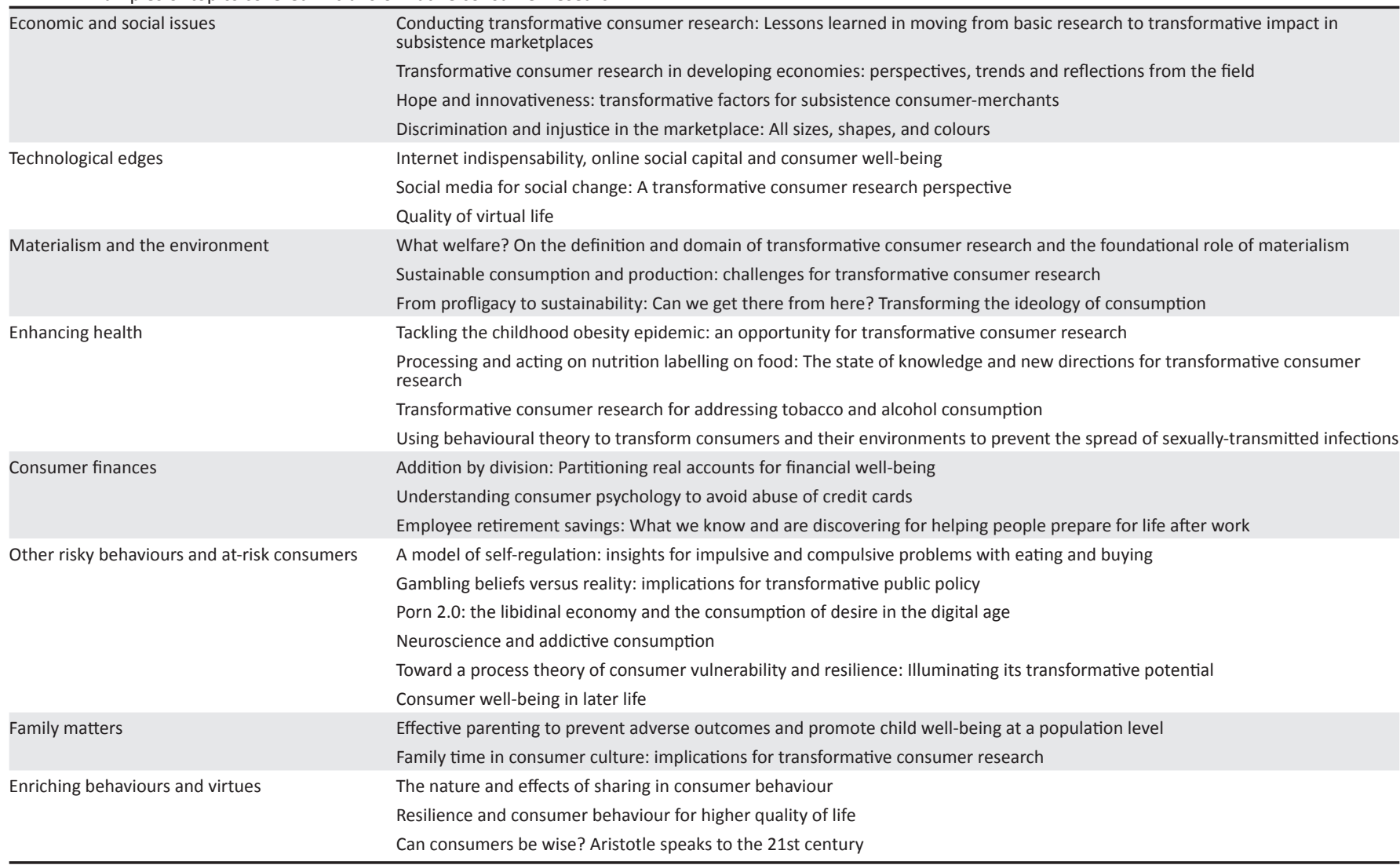

Source: Adapted from Mick, D.G., Pettigrew, S., Pechmann, C., \& Ozanne, J.L. (2012a). Origins, qualities and envisionments of transformative consumer research. In D.G. Mick, S. Pettigrew, C. Pechmann, \& J.L. Ozanne, (Eds.), Transformative consumer research for personal and collective well-being (pp. vii-x). New York: Taylor \& Francis 
In terms of economic and social issues, it may be worthwhile investigating which types of discrimination and injustice vulnerable consumers experience in the South African marketplace and how this can be addressed. Some areas in South Africa are characterised by high levels of organised crime. What keeps children growing up in areas characterised by organised crime from taking part in these types of acquisition and becoming part of the prevalent culture in their areas?

In terms of technological edges, Nair (2013) points to global privacy concerns ensuing from the ubiquity of the internet. These concerns include governmental surveillance of citizens and companies using big data to gain insight into the behaviour of customers and staff. Since improved technology may increase the speed of consumption and enhance its affordability, it may escalate environmental destruction and resource depletion. Institutions such as government bodies, private watchdogs and international agencies that regulate the relationship between consumption and the requirement for conserving and protecting experience increased pressure because of the shortened product life cycle often brought about by technology.

In terms of materialism and the environment, impoverished people are exposed to advertising and the consumption rituals it portrays. It may be worthwhile investigating how people such as these deal with the expectations created by portrayed rituals such as gifting at Christmas or birthdays when they do not have the necessary means to fulfil these expectations.

In terms of enhancing health, Usfar et al. (2010) point out that obesity contributes significantly to global issues of chronic disease and disability. In developing countries, obesity often relates to under-nutrition. Child (2013) further points out that some South Africans' lifestyles increase their vulnerability to diabetes, strokes, heart attacks and certain types of cancers. An estimated $60 \%$ of South Africa women are overweight or obese, the country's preschool children are amongst the most overweight globally and many South African adults consume too much sugar and fat. Drewnowski (2012) points out in this regard that effective obesity prevention and treatment strategies critically depend on knowing the environmental context of widespread national obesity.

Related to the area of consumer finances, the National Credit Regulator (NCR) (SAPA, 2013) warns that South Africans 'are drowning in debt'. Mouton (2013) further reports that part of the salaries of more than half a million South Africans are earmarked for debt repayment. Attachments, sometimes known as 'garnishee orders', force employers to deduct debt instalments from employees' salaries. The latest statistics from the National Credit Regulator show that more than 9.5 million South Africans have impaired credit records.

Related to the area of other risky behaviour and at-risk consumers, Louw (2013) points out a steady growth in addiction to pornography in South Africa. Maintaining an addiction to pornography may be expensive, but most Internet pornography users only access free material (for instance, samples), pirated versions of paid material or amateur material. The access and the availability of pornographic material contribute significantly to the increase in addiction to pornography in this country.

In terms of family matters, several experts believe that the disintegration of South African family life may be partly responsible for numerous social problems such as school violence and the rape of children. Narsee (2013) reports on a few trends that illustrate the breakdown of (traditional) family life such as more than 90000 children living in childheaded households, nearly half of South African children being from single-parent households and about $60 \%$ of South African children being born to unmarried mothers.

In investigating ways to effectively market to BOP consumers, Chikweche et al. (2012) identified several changing family buying models. The constraints that BOP consumers face as well as the distinctive roles of children, differing from those in developed countries, are reflected in these models. Chikweche et al. (2012) point out that the majority of international business studies have focused on Latin America and Asia, overlooking the 800 million BOP consumers in Africa. Although these studies focus on marketing to BOP consumers and not their common consumption concerns, they provide some indication of the vast number of consumers who may benefit from transformative consumer research and that family decision-making may take on different forms than in a customary Western environment.

In terms of enriching behaviour and virtues, Belk (in press) points to a considerable amount of recent research on a cluster of business and consumption practices described, for instance, as sharing (Belk, 2010), collaborative consumption (Botsman \& Rogers, 2010) and online volunteering (Postigo, 2003). Established businesses that reflect the 'sharing economy' include Wikipedia, Flickr and Twitter. A common attribute that underlies these sharing and collaborative consumption practices are that participants rely on the Internet, especially Web 2.0, to achieve their goals. Belk (in press) further states that 'sharing is a phenomenon as old as humankind' and that a commonly accepted conception in consumer psychology, namely that we are what we own, may need to be adapted to consider additional types of possession and uses that do not centre around ownership. At a concrete level, it is known that BOP consumers employ sharing to fully exploit their limited resources. This trend should probably be included in such adaptations to represent the full range of consumer sharing.

Finally, it may be worthwhile investigating effective ways of providing information about health risks and nutritional information to consumers with limited literacy levels. An additional area of interest would be how consumer education may build on existing virtues amongst consumers in a developing country context to increase their awareness of possible vulnerabilities and how to circumvent them. 


\section{Incorporating transformative consumer research into higher education curricula}

Transformative consumer research is gradually being incorporated into the curricula of a few higher-education institutions. Mari (2008) suggests a possible framework for incorporating a transformative consumer-research orientation into doctoral programmes, especially for establishing the awareness that it serves as an alternative approach for conducting consumer research. Petkus (2010) extends Mari's (2008) suggestion for undergraduate marketing education by outlining the relevance of transformative consumer research to undergraduate consumer behaviour courses. He further suggests topics that could be addressed as well as ways in which courses could be structured to incorporate transformative consumer research.

The field of transformative consumer research is covered in both the Research Proposal in Consumer Psychology and Research Project in Consumer Psychology courses that are presented at honours level at the University of South Africa. The author suggests that students at undergraduate level in the South African higher-education environment be introduced to this field in related curricula to establish an awareness of the potential that such consumer research holds. If students are exposed to the basics of transformative consumer research and the consumer well-being issues that these raise, they may realise that the behaviour and experiences of all consumers, especially in the context of a developing country, do not necessarily correspond to the views espoused in traditional models on consumer decisionmaking.

The author supports Petkus's (2010) suggestion that incorporating transformative consumer research into higher-education curricula does not imply a radical review of consumer-behaviour or consumer-psychology curricula. Transformative consumer research presents a counterpart to the prevalent managerial focus in consumer research but not necessarily a replacement. The rationale for incorporating transformative consumer research into consumer-behaviour and consumer-psychology curricula, in particular, rests on the notion that such curricula introduce students to consumer research in its entirety and that popular models and theories may not sufficiently serve as bases for explaining consumer behaviour in the context of a developing country. It is envisaged that this development will eventually result in sustained research about the relationship between the wellbeing of consumers at all levels of society and the impact that consumption has on this state of existence.

\section{Discussion}

The objective of this study was to investigate how the field of transformative consumer research can enhance the relevance of consumer research in the context of a developing country. All in all, the goals of transformative consumer research are to promote, guide and cultivate a new generation of consumer research on well-being that is conceptually rich, methodologically sound and has practical significance.
Incorporating transformative consumer research into traditional research approaches should improve the internal and external relevance of consumer research in the context of a developing country. A transformative consumer-research approach may, for instance, address some of the 'seven sins' of consumer psychology, as identified by Pham (2013). Some of the suggestions that he offers for alleviating these fundamental problems in current consumer research indeed may be embedded in a transformative consumer-research approach as pointed out below.

Pham (2013) suggests extending the scope of consumer research beyond purchase behaviour. Mainly supporting Pham's suggestions, this article initially pointed out the relevance of investigating additional areas in consumer research such as less-considered types of acquisition, additional stages of consumer behaviour and the psychology of consumption-need deprivation. The article elaborated on some of Pham's recommendations by pointing out trends that may occur in the context of a developing country such as the restrictions that BOP consumers face and the phenomenon of consumer vulnerability. This article added to Pham's (2013) views by pointing out that trends such as these may limit the applicability of commonly accepted consumer decisionmaking models in the context of a developing country. All in all, transformative consumer research typically widens the range of problems investigated as well as the stakeholders reached (Crocket et al., 2013).

Pham (2013) recommends that consumer researchers should adopt a broader set of theoretical perspectives and focus less intently on identifying what he terms unique, micro-level explanations. Enhancing the relevance of consumer research requires an acknowledgement that there may be multiple explanations for a particular phenomenon, even at different levels. Yadav (2010), for instance, advises that, in light of the complexity of transformative consumer-research issues, it is essential to develop new theories and to investigate their significance in consumer research.

Pham (2013) suggests that consumer psychologists should expand their epistemology by diverging from the traditional theory-driven path in consumer research and considering alternative approaches such as inductive research and field-theory validations. Corresponding to this suggestion, transformative consumer research does not prescribe a particular paradigm, theory or method unless the focus, challenges, intended audience and uses of a research study are evident.

A further requirement for enhancing the relevance of consumer research is a more in-depth focus on the psychological contents of consumer behaviour (including the contents of consumers' thoughts, feelings and actions) rather than the psychological processes involved. The aim of consumer research would therefore not necessarily be to identify universally accepted principles but rather to determine the applicability of theories in particular consumption contexts. Mick et al. (2012a), for instance, believe 
that the requisite contextual consideration in transformative consumer research will enrich theory building and add to existing theories.

Finally, Pham (2013) refers to one of the 'seven sins' of consumer psychology as 'research by convenience'. A trend contributing to this fundamental problem in consumer research is that student samples are often used to investigate the experiences of consumers in general, which is regarded as debatable. Pham (2013) suggests investigating the reallife behaviour of real consumers in, for instance, field studies. A broader range of consumers from a variety of socioeconomic conditions and markets should be sampled. It is evident that a transformative consumer-research approach, amongst others, offers the possibility for investigating the consumption experiences and well-being of consumers who are not typically reflected in existing consumer research, especially those from developing countries.

\section{Limitations of the study}

One of the core commitments of transformative consumer research is to emanate from the ACR and encourage paradigm diversity. The author believes that, although South African researchers can learn from the traditions of the ACR, they do not necessarily have to be members of the ACR to set a transformative consumer-research agenda. The organisation of transformative consumer research would be an important initial step in this country and would enable researchers who support this approach to collaborate and sustain relevant research.

Despite an increasing interest in the issues typically addressed in transformative consumer research, this type of research is not considered mainstream since most consumer researchers still tend to generate knowledge that will be used at managerial level in commercial organisations (Askegaard \& Scott, 2013; Ozanne et al., 2011). Researchers who want to follow this route may therefore face a number of hurdles such as limited funding and promotion opportunities.

Crockett et al. (2013) further point out that research methods that simplify and reduce constructs and theories to achieve validity are often considered more scientific than those that may be socially relevant. Crockett et al. (2013) suggest that reputable, established scholars should take the lead in compiling research teams that address complex social problems. In the light of widespread public concern over current social, economic and political issues, sound, evidencebased ideas and findings would make a valuable contribution. Consumer researchers may particularly contribute towards understanding such problems since many stem from market and consumption conditions.

\section{Future research opportunities}

Pancer and Handelman (2012) suggest that incorporating more community-oriented and contextually-bound criteria into an understanding of consumer well-being may generate new research insights. Since one of its principles is to highlight socio-cultural and situational contexts, transformative consumer research may be particularly relevant for investigating consumer well-being in a country such as South Africa, known for its cultural diversity (Higgs, 2007).

Pham (2013) believes that consumer psychology needs to urgently re-assess its relevance. Consumer research currently does not offer sufficient relevance for its external stakeholders (businesses, policy makers and consumers in general), and the largest part of consumer research may not even be particularly relevant to its internal stakeholders such as other consumer researchers and social scientists. Although this article highlights the plight of vulnerable consumers, transformative consumer research is clearly not limited to investigating the experiences of these consumers. A transformative consumer approach indeed encourages investigating a broader range of topics in consumer research. Some of the identified topics such as the high indebtedness of South African consumers, the degeneration of family life and the impact of technological change on most spheres of life may warrant further research attention. To truly investigate these phenomena from various perspectives would require the involvement of various stakeholders such as governmental agencies, consumer protection bodies and input from various disciplines and consumers themselves.

\section{Conclusion}

The author recommends that researchers empirically investigate some of the propositions underlying the transformative consumer-research approach to enhance the relevance of consumer research to both its internal and external stakeholders. The extent to which future studies address real-life, recurring South African consumerbehaviour issues may signify their relevance for consumer research in this country.

\section{Acknowledgements Competing interests}

The author declares that she has no financial or personal relationship(s) that may have inappropriately influenced her in writing this article.

\section{References}

Al-Wugayan, A.A. \& Suprenant, C.F. (2006). Examining the relationship between personal, cultural values and desired benefits: A cross-national study. In C.P. Rau (Ed.), Marketing and multicultural diversity (pp. 31-52). Hampshire: Ashgate Publishing Limited.

Andreasen, A.R., Goldberg, M.E., \& Sirgy, M.J. (2012). Foundational research on consumer welfare: Opportunities for a transformative consumer research agenda. In D.G. Mick, S. Pettigrew, C. Pechmann, \& J.L. Ozanne, J.L (Eds.), Transformative consumer research for personal and collective well-being (pp. 25-66). New York: Taylor \& Francis.

Arnould, E.J., \& Thompson, C.J. (2005). Consumer culture theory (CCT): Twenty years of research. Journal of Consumer Research, 31(4), 868-882. http://dx.doi. org/10.1086/426626

Askegaard, S., \& Scott, L. (2013). Consumer culture theory: The ironies of history. Marketing Theory, 13(2), 139-147. http://dx.doi.org/10.1177/1470593113479007

Baker, M.J. (2011). Editorial - Why 'social business'?. Social Business, 1(1), 1-15. http://dx.doi.org/10.1362/204440811X570536

Banerjee, A. \& Duflo, E. (2006). The economic lives of the poor. Journal of Economic Perspectives, 21(1), 141-167. http://dx.doi.org/10.1257/jep.21.1.141 
Belk, R. (1988). Possessions and the extended self. Journal of Consumer Research, 15 (1), 139-168. http://dx.doi.org/10.1086/209154

Belk, R. (2010). Sharing. Journal of Consumer Research, 36(5), 715-734.

Belk, R. (in press). You are what you can access: Sharing and collaborative consumption online. Journal of Business Research.

Bertrand, M., Mullainathan, S. \& Shafir, E. (2006). Behavioral economics and marketing in aid of decision making among the poor. Journal of Public Policy and Marketing 25(1), 8-23. http://dx.doi.org/10.1509/jppm.25.1.8

Blackwell, R.D., Miniard, P.W., \& Engel, J.F. (2006). Consumer behaviour. (10th edn.). Mason, Ohio: Thomson, South-Western.

Blocker, C.P., Ruth, J.A., Sridharan, S., Beckwith, C., Ekici, A., Goudie-Hutton, M., e al. (2013). Understanding poverty and promoting poverty alleviation through transformative consumer research. Journal of Business Research, 66(8), 11951202. http://dx.doi.org/10.1016/j.jbusres.2012.08.012

Boote, D.N., \& Beile, P. (2005). Scholars before researchers: On the centrality of the dissertation literature review in research preparation. Educational Researcher 34(6), 3-15. http://dx.doi.org/10.3102/0013189X034006003

Botsman, R., \& Rogers, R. (2010). What's mine is yours: The rise of collaborative consumption. New York, NY: Harper Collins.

Burke, D., \& Evans, J. (2011). Embracing the creative: The role of photo novella in qualitative nursing research. International Journal of Qualitative Methods, 10(2) 164-177.

Chikweche, T., Stanton, J., \& Fletcher, R. (2012). Family purchase decision making at the bottom of the pyramid. Journal of Consumer Marketing, 29(3), 202-213. http://dx.doi.org/10.1108/07363761211221738

Child, K. (2013). Obesity in SA tips the scales. Retrieved January 4, 2014, from http:// www.timeslive.co.za/thetimes/2013/02/06/obesity-in-sa-tips-the-scales

Crockett, D., Downey, H., Firat, A.F., Ozanne, J. L., \& Pettigrew, S. (2013) Conceptualizing a transformative research agenda. Journal of Business Research, 66(8), 1171-1178. http://dx.doi.org/10.1016/j.jbusres.2012.08.009

Downey, H., Hamilton, K., \& Catterall, M. (2007). Researching vulnerability: What about the researcher? European Journal of Marketing, 41(7/8), 734-739. http:// dx.doi.org/10.1108/03090560710752375

Drewnowski, A. (2012). The economics of food choice behavior: Why poverty and obesity are linked. Retrieved January 4, 2014, from https://www.nestlenutritioninstitute.org/intl/zh/resources/library/Free/workshop/NNIWBOOK73/ institute.org/intl/zh/resources/library

Eckhardt, G.M., \& Mahi, H. (2012). Globalization, consumer tensions, and the shaping of consumer culture in India. Journal of Macromarketing, 32(3), 280-294. http:// dx.doi.org/10.1177/0276146712440708

Evans. M., Jamal, A., \& Foxall, G.R. (2009). Consumer behaviour. (2nd edn.). Hoboken, NJ: Wiley.

GangImair-Wooliscroft, A., \& Lawson, R. (2011). Subjective well-being of different consumer lifestyle segments. Journal of Macromarketing, 31(2), 172-183. http:// dx.doi.org/10.1177/0276146710393251

Hart, S.H. (2002). The world economic pyramid. Johannesburg, SA: World Business Council for Sustainable Development.

Henrich, J., Heine, S.J., \& Norenzayan, A. (2010). The weirdest people in the world. The Behavioral and Brain Sciences, 33(2/3), 61-83. http://dx.doi.org/10.1017/ S0140525X0999152X

Higgs, N.T. (2007). Measuring and understanding the well-being of South Africans: Everyday quality of life in South Africa. Social Indicators Research, 81(2), 331-356. http://dx.doi.org/10.1007/s11205-006-9012-3

Hill, R.P. (2001) Surviving in a material world: The lived experience of people in poverty. South Bend, IN: University of Notre Dame Press.

Jones, M. (2013). Conspicuous destruction, aspiration and motion in the South African Township. Safundi, 14(2), 209-224. http://dx.doi.org/10.1080/17533171.2013.7 76749

Klein, J.T. (2008). Evaluation of interdisciplinary and transdisciplinary research: A literature review. American Journal of Preventive Medicine, 35(2 S), S116-S123. literature review. American Journal of Preventive
$\mathrm{http}: / / \mathrm{dx}$.doi.org/10.1016/j.amepre.2008.05.010

Louw, P. (2013). Hooked on porn. The Times. Retrieved January 5, 2014, from http:// www.timeslive.co.za/thetimes/2013/11/25/hooked-on-porn

Mari, C. (2008). Doctoral education and transformative consumer research. Journal of Marketing Education, 30(1), 5-11. http://dx.doi.org/10.1177/0273475307312194

McGregor, S.L.T. (2013). Transdisciplinary consumption. Integral Review: A Transdisciplinary and Transcultural Journal, 9(2), 413-438.

McGregor, S.L.T., \& Goldsmith, E.B. (1998). Expanding our understanding of quality of life, standard of living, and well-being. Journal of Family and Consumer Sciences, $90(2), 2-6$

Menzel Baker, S.M., Gentry, J.W., \& Rittenburg, T.L. (2005). Building understanding of the domain of consumer vulnerability. Journal of Macromarketing, 25(2), 128139. http://dx.doi.org/10.1177/0276146705280622

Mick, D.G. (2006). ACR presidential address: Meaning and mattering through transformative consumer research. Advances in Consumer Research, 33, 2-5.

Mick, D.G., Pettigrew, S., Pechmann, C., \& Ozanne, J.L. (2012a). Origins, qualities and envisionments of transformative consumer research. In D.G. Mick, S. Pettigrew, C. Pechmann, \& J.L. Ozanne, (Eds.), Transformative consumer research for personal and collective well-being (pp. 3-24). New York: Taylor \& Francis.

Mick, D.G., Pettigrew, S., Pechmann, C., \& Ozanne, J. L. (2012b). Preface. In D.G. Mick, S. Pettigrew, C. Pechmann, \& J.L. Ozanne, (Eds.), Transformative consumer research for personal and collective well-being (pp. xv-xvii). New York: Taylor \& Francis.
Minkler, M., \& Wallerstein, N. (2003). Introduction to community based participatory research. In M. Minkler \& N. Wallerstein (Eds.), Community-based participatory research for health (pp. 2-26). San Francisco: Jossey-Bass.

Mkhwanazi, J.P. (2011). Conspicuous consumption and black youth in emerging markets. MBA dissertation, University of Pretoria, Pretoria, South Africa, viewed May 12, 2013, from http://upetd.up.ac.za/thesis/available/etd-07212012184356/

Mouton, S. (2013). Easy credit 'a cause of labour strife'. Retrieved January 6, 2014 from http://www.timeslive.co.za/thetimes/2013/10/11/easy-credit-a-cause-oflabour-strife

Nair, C. (2013). Five dangers the internet poses to a sustainable world. The Guardian. Retrieved January 4, 2014, from http://www.theguardian.com/sustainablebusiness/five-dangers-internet-poses-world

Nairn, A., Griffin, C., \& Wicks, P.G. (2008). Children's use of brand symbolism: A consumer culture theory approach. European Journal of Marketing, 42(5/6), 627-640. http://dx.doi.org/10.1108/03090560810862543

Narsee, A.J. (2013). 'SA families are in crisis'. Retrieved January 6, 2014, from http:// www.timeslive.co.za/thetimes/2013/12/18/sa-families-are-in-crisis

Ortlipp, M. (2008). Keeping and using reflective journals in the qualitative research process. The Qualitative Report, 13(4), 695-705.

Ozanne, J.L., Pettigrew, S., Crockett, D., Downey, H., Firat, A.F., \& Pescud, M. (2011). The practice of transformative consumer research: Some issues and suggestions. Journal of Research for Consumers, 19, 1-7.

Ozanne, J.L., \& Saatcioglu, B. (2008). Participatory action research. Journal of Consumer Research, 35(3), 423-439. http://dx.doi.org/10.1086/586911

Pancer, E., \& Handelman, J. (2012). The evolution of consumer well-being. Journal of Historical Research in Marketing, 4(1), 177-189. http://dx.doi. org/10.1108/17557501211195118

Petkus, E. (2010). Incorporating transformative consumer research into the consumer behaviour course experience. Journal of Marketing Education, 32(3), 292-299. http://dx.doi.org/10.1177/0273475310377784

Pettigrew, S. (2011). Where to from here? Journal of Research for Consumers, 20, $1-10$.

Pham, M.T. (2013). The seven sins of consumer psychology. Journal of Consumer Psychology, 23 (4), 411-423. http://dx.doi.org/10.1016/j.jcps.2013.07.004

Piacentini, M., \& Hamilton, K. (2013). Consumption lives at the bottom of the pyramid Marketing Theory, 13(3), 397-400. http://dx.doi.org/10.1177/1470593113489195

Point of Purchase Advertising International (POPAI) (n.d.). Gini coefficient amongst highest. Retrieved March 25, 2014, from http://www.popai.co.za/gini-coefficientamongst-highest

Postigo, H. (2003). Emerging sources of labor on the Internet: The case of America online volunteers. International Review of Social History, 48, 205-223. http:// dx.doi.org/10.1017/S0020859003001329

Rangan, V.K., Quelch, J.A., Herrero, G., \& Barton, B. (2007). Business solutions for the global poor. New York, NY: Wiley.

SAPA. (2013). South African consumers drowning in debt: NCR. Retrieved January 5 , 2014, from http://www.timeslive.co.za/local/2013/12/04/south-africanconsumers-drowning-in-debt-ncr

Schiffman, L.G., Kanuk, L.L., \& Wisenblit, J. (2010). Consumer behaviour. (10th edn.). Upper Saddle River, N.J.: Pearson Education/Prentice Hall.

Schultz, C.J., \& Shapiro, S.J. (2012). Transformative consumer research in developing economies: Perspectives, trends and reactions from the field. In D.G. Mick, S Pettigrew, C. Pechmann, \& J.L. Ozanne (Eds.), Transformative consumer research Pettigrew, personal and collective well-being (pp. 131-150). New York: Taylor \& Francis.
for

Shevel, A., \& Klein, M. (2008, 24 February). SA's wealth distribution 'is a timebomb'. Sunday Times Business Times, p. 8.

Sirgy, M.J., Lee, D., \& Rahtz, D. (2007). Research on consumer well-being (CWB): Overview of the field and introduction to the special issue. Journal of Macromarketing, 27(4), 341-349. http://dx.doi.org/10.1177/0276146707307212

Sirgy, M.J., Lee, D., \& Rahtz, D. (2008). Well-being marketing: An ethical business philosophy for consumer goods firms. Journal of Business Ethics, 77(4), 377-403. http://dx.doi.org/10.1007/s10551-007-9363-y

Solomon, M.R., Askegaard. S., \& Bamossy, G.J. (2006). Consumer behaviour: A European perspective. New York: Prentice Hall Europe.

Stokols, D., Misra, S., Moser, R.P., Hall, K.L., \& Taylor, B.K. (2008). The ecology of team science understanding contextual influences on transdisciplinary collaboration. American Journal of Preventive Medicine, 35(2 S), S96-S115.

Ungerer, L.M. (2013). The relationship of South African consumers' living standards and demographic variables with their life satisfaction. In H. Knoop \& A. Delle Fave, (Eds.), Well-being and cultures: Perspectives from positive psychology (pp. 135159). Dordrecht: Springer Science + Business Media.

Usfar, A.A., Lebenthal, E., Achadi, E., \& Hadi, H. (2010). Obesity as a poverty-related emerging nutrition problem: The case of Indonesia. Obesity reviews, 11(12), 924928. http://dx.doi.org/10.1111/j.1467-789X.2010.00814.x

Wansink, B. (2012). Activism research: Designing transformative lab and field studies. In D.G. Mick, S. Pettigrew, C. Pechmann, \& J.L. Ozanne (Eds.), Transformative consumer research for personal and collective well-being (pp. 67-88). New York: Routledge.

Wratten, E. (1995). Conceptualizing urban poverty. Environment and Urbanization, 7, 11-38. http://dx.doi.org/10.1177/095624789500700118

Wilson, E.O. (1998). Consilience. New York: Alfred. A. Knopf.

Yadav, M.S. (2010). The decline of conceptual articles and implications for knowledge development. Journal of Marketing, 74(1), 1-19. http://dx.doi.org/10.1509/ jmkg.74.1.1 